\title{
Intergranular Stress Corrosion Crack Propagation in Sensitised Austenitic Stainless Steel (Microstructure Modelling and Experimental Observation)
}

Link to publication record in Manchester Research Explorer

Citation for published version (APA):

Marrow, T. J., Jivkov, A., Wood, P., Engelberg, D., Babout, L., Anyachor, N., Stevens, N., Withers, P., Newman, R., \& Gdoutos, E. L. (Ed.) (2006). Intergranular Stress Corrosion Crack Propagation in Sensitised Austenitic Stainless Steel (Microstructure Modelling and Experimental Observation). In E. L. Gdoutos (Ed.), Proceedings of the 16th European Conference of Fracture Springer Nature.

\section{Published in:}

Proceedings of the 16th European Conference of Fracture

\section{Citing this paper}

Please note that where the full-text provided on Manchester Research Explorer is the Author Accepted Manuscript or Proof version this may differ from the final Published version. If citing, it is advised that you check and use the publisher's definitive version.

\section{General rights}

Copyright and moral rights for the publications made accessible in the Research Explorer are retained by the authors and/or other copyright owners and it is a condition of accessing publications that users recognise and abide by the legal requirements associated with these rights.

\section{Takedown policy}

If you believe that this document breaches copyright please refer to the University of Manchester's Takedown Procedures [http://man.ac.uk/04Y6Bo] or contact uml.scholarlycommunications@manchester.ac.uk providing relevant details, so we can investigate your claim.

\section{OPEN ACCESS}




\title{
INTERGRANULAR STRESS CORROSION CRACK PROPAGATION IN SENSITISED AUSTENITIC STAINLESS STEEL (MICROSTRUCTURE MODELLING AND EXPERIMENTAL OBSERVATION)
}

\author{
T.J. Marrow*, A.P. Jivkov, P. Wood, D. Engelberg, L. Babout, N. Anyachor, N. Stevens, \\ P.J. Withers, School of Materials, University of Manchester, UK and \\ R.C. Newman, Department of Chemical Engineering and Applied Chemistry, University \\ of Toronto, Canada \\ ${ }^{*}$ Corresponding Author (James.Marrow@manchester.ac.uk)
}

\begin{abstract}
Three dimensional observations of intergranular stress corrosion crack nucleation and growth in sensitised austenitic stainless steel provide evidence for the development of crack bridging ligaments, caused by the resistance of non-sensitised special grain boundaries. A simple grain bridging model, introduced to quantify the effect of crack bridging on crack development, has been assessed via statically loaded room temperature tests, as well as high temperature/pressure water autoclave studies. Thermo-mechanical treatments have been used to modify the microstructure of type 304 austenitic stainless steel. Grain refinement has a significant beneficial effect on crack growth resistance. A beneficial effect of the residual stresses from surface machining is observed and compares well with the model prediction. Two and three-dimensional finite element models of intergranular crack propagation have been developed, which are consistent with the observed effects of microstructure. These models have the potential to be developed to describe the kinetics of short intergranular stress corrosion crack growth and coalescence.
\end{abstract}

\section{Experimental Observations}

"Grain Boundary Design and Control" [1] aims to improve the intergranular corrosion (IGC) and intergranular stress corrosion cracking (IGSCC) resistance of materials. The grain boundary network is characterised by the crystallographic relationships between adjacent grains. Grain boundary engineering, achieved by thermal and thermo-mechanical processing, is typically applied to low and medium stacking fault energy face centred cubic (FCC) materials, such as stainless steels, and is typically used to increase the fraction of low energy, "special", grain boundaries.

The grain orientation populations, and hence the grain boundary network, are obtained by Electron Backscatter Diffraction (EBSD) techniques [2]. Crystallographic as well as spatial information is recorded, and is used to determine a Grain Boundary Character Distribution (GBCD), which is representative of the microstructure. The GBCD is a discrete population of grain boundary types, based on either their frequencies or relative length fractions. EBSD may also be used to study the interaction of stress corrosion cracks with microstructure (Figure 1), in order to identify resistant and susceptible boundaries [3].

a)

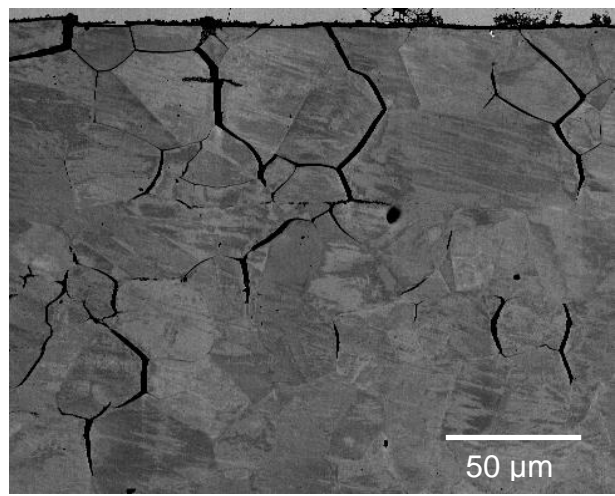

b)

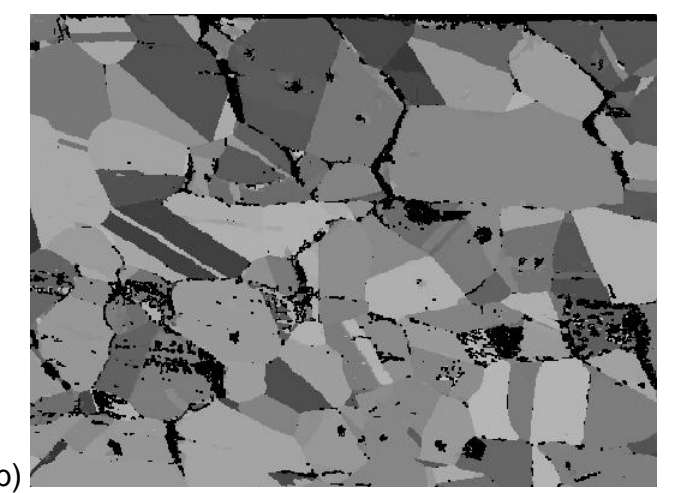

Figure 1: EBSD analysis of cracks obtained in high temperature autoclave conditions under static load a) backscatter electron image b) EBSD data for the same region - the grey levels indicate different grain orientations, from which grain boundary character can be derived. The cracks have propagated from the surface of the specimen, which is at the upper edge of the image. 
The interaction between a propagating intergranular stress corrosion crack and the microstructure has been investigated by in-situ three dimensional observations of intergranular stress corrosion cracking, using the ID19 X-ray microtomography beam line at the European Synchrotron Radiation Facility (ESRF), France [4]. An annealed and fully sensitised type 302 stainless steel wire (400 $\mu \mathrm{m}$ diameter) was tested in $0.15 \mathrm{M}$ potassium tetrathionate $\left(\mathrm{K}_{2} \mathrm{~S}_{4} \mathrm{O}_{6}\right)(\mathrm{pH} 2)$.

The progressive failure of crack bridging ligaments was observed (Figure 2). Correlation of the tomography analysis with fractography confirmed that the ligaments produced ductile features, which had a morphology that was consistent with non-sensitised grain boundaries [4]. Such boundaries are commonly found to have a high degree of coincidence between the crystal lattice orientations of the grains, which may be described using the coincidence site lattice (CSL) model. Twin boundaries ( $\Sigma 3$ ) and some low CSL boundaries with $\Sigma \leq 29$ are found to be generally resistant to intergranular corrosion and stress corrosion cracking, although this may vary with environment [3]. These observations show that non-sensitised boundaries are resistant to stress corrosion cracking, and the crack propagates around the obstacle formed by these ligaments. The ductile failure of the ligaments is expected to shield the crack tip from the applied stress. The shielding mechanism is analogous to fibre composite mechanics.

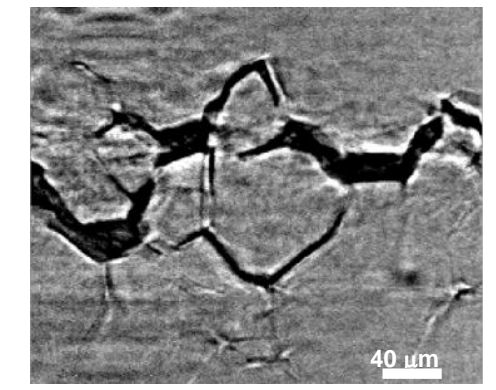

a)

Figure 2: Tomographic data obtained at the same location inside the sample at successive periods (a and b) during stress corrosion cracking of sensitised type 302 stainless steel wire. Progressive failure of crack bridging ligaments is observed.

The effects of thermo-mechanical processing on the stress corrosion cracking resistance of sensitised type 304 austenitic stainless steel has therefore been studied [3-5], based on the proposition that resistance to stress corrosion cracking develops from crack bridging, which is a consequence of grain boundary triple junctions with one or more resistant grain boundaries (i.e. non-sensitised boundaries). Crack propagation depends on the frequency of resistant triple junctions encountered by the crack tip, thus both grain size and the grain boundary character distribution are predicted to be significant parameters. Grain boundary engineering to increase the contribution from crack bridging ligaments through an increase in the frequency of annealing twins, for example, may be expected to improve stress corrosion cracking resistance.

Crack propagation tests have been performed to evaluate the population of short stress corrosion cracks that are developed under static stress. Under such conditions, equilibrium can develop between the applied stress and the shielding stresses arising from crack bridging. Several microstructures of fully sensitised type 304 austenitic stainless steel were examined using a room temperature low pH thionate solution and a high temperature autoclave environment which gave conditions relevant to high purity water under oxidising conditions. Details of the tests are published elsewhere [4]. The crack depths are observed to have a lognormal population, and hence extreme value statistics, in the form of Gumbel distributions, were applied to evaluate the crack population. This method allows the extremes of a large crack population to be described by measuring the deepest cracks in the sample cross-section. Comparisons are made at equivalent values of the reduced parameter, y [4].

Typical results are given in Figure 3, which illustrates a significant influence of microstructure on crack propagation. Increasing the applied tensile stress has also been shown to increase the maximum crack length in the thionate solution, independent of test duration [4]. The $30 \% / 900 / 30$ microstructure has a reduced grain size $(11 \mu \mathrm{m})$ and lower fraction $(27 \%)$ of twin and low CSL boundaries compared to the asreceived microstructure $\left(27 \mathrm{um}\right.$ and $35 \%$ ). It was cold worked by $30 \%$ and annealed at $900^{\circ} \mathrm{C}$ for 30 minutes. Twin boundaries $(\Sigma 3)$ were not counted in the grain size measurements. Including twins gives average grain size of $10 \mu \mathrm{m}$ and $21 \mu \mathrm{m}$ for the 30\%/900/30 and as-received microstructures respectively. Crack propagation rates were significantly slower in the autoclave environment, and the cracks here may not have reached equilibrium in the test duration. Both microstructures were fully sensitised and the dominant effects appears to be the refinement of the grain size. 
a)
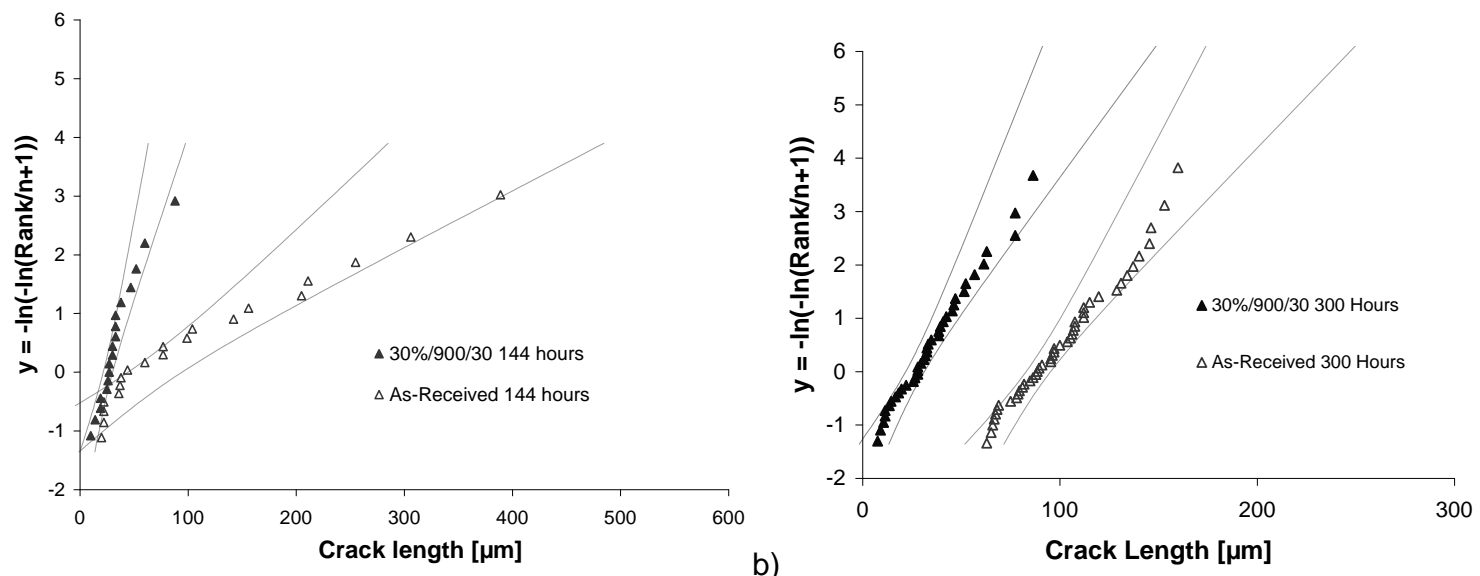

Figure 3: Crack population data, expressed as the reduced variant $(\mathrm{y})$ as a function of the observed crack length for the $30 \% / 900 / 30$ and as-received microstructures tested in a) $0.1 \mathrm{M}$ potassium tetrathionate solution, acidified with diluted sulphuric acid to $\mathrm{pH} 2.5$, under an applied stress of $100 \mathrm{MPa}$ for 144 hours., b) $0.01 \mathrm{M} \mathrm{Na}_{2} \mathrm{SO}_{4}$ electrolyte at $250^{\circ} \mathrm{C}$ and $40 \mathrm{bar}, 500 \mathrm{mV}$ above rest potential, under an applied stress of $244 \mathrm{MPa}$ for 300 hours. Dashed lines are the $95 \%$ confidence limits for the extreme vale distribution fitted to the data.

\section{Simple Analytical Model}

An analytical model has been developed to predict the effects of crack bridging grain boundaries $[4,5]$. The objective was to quantify the relative effects of grain size and fraction of resistant grain boundaries, and to include the effects of applied stress. The probability, $P$, of crack bridge formation at a triple junction is expressed by equation (1). The expression chosen for $P$ is similar that used in percolation-like models [6, 7], and gives approximately the ratio of the number of triple junctions with potential to form crack bridges to the total number available to the crack tip. Here, $f_{T J(n-C S L)}$ is the frequency of occurrence of triple junctions with $n$ resistant boundaries (i.e. non-sensitised low CSL, $\Sigma \leq 29$ ) and $f_{a}$ and $f_{b}$ are geometrical factors (assumed to be 1 and 0.5 respectively), which may account for unfavourably oriented sensitised boundaries at the triple junction. The ratio of $f_{T J(1-C S L)}$ to $f_{T J(2-C S L)}$ does not vary significantly over a wide range of microstructures, thus the actual values of $f_{a}$ and $f_{b}$ are not critical in the relative ranking of microstructures. EBSD does not reliably characterise all triple junctions due to resolution limitations and data scatter, although data which is sufficiently representative to evaluate microstructures can be obtained when a sufficient number of grains is characterised.

$$
P=\frac{\left(f_{a} f_{T J(2-C S L)}+f_{b} f_{T J(1-C S L)}\right)}{1-f_{T J(3-C S L)}}
$$

The probability, $X$, that the crack tip will encounter a resistant triple junction as it propagates a distance $L$ may be expressed using equation (2). The distance, over which there is a critical probability of bridge formation, say $L_{99 \%}$ for $X=99 \%$, will be related to the average distance between crack bridging ligaments on the fracture surface. Since there is a probability that bridging may not develop for a short stress corrosion crack nucleated at a surface until the crack length exceeds $L_{99 \%}$, the average crack bridging stress, $\sigma_{b}$, will vary with length $(a)$ for short cracks, rising to a maximum value $\sigma_{b m a x}$ with a form such as equation (3). The crack bridging stress acts to shield the crack tip from the applied stress.

$$
\begin{gathered}
X=1-(1-P)^{2 L / D} \\
\sigma_{b}=\left(\frac{a-L_{99 \%}}{a}\right) \sigma_{b \max } \text { for } a>L_{99 \%}, \sigma_{b}=0 \text { for } a \leq L_{99 \%}
\end{gathered}
$$

The magnitude of the crack bridging stress induced by the ligaments is difficult to determine using a simple model, since with increasing crack opening displacement relative to the ligament size, the ligaments may deform elastically, yield or rupture. A constant maximum crack bridging stress, $\sigma_{b \max }$, is currently assumed for all microstructures. If this is sufficient to arrest or significantly retard crack propagation, then 
microstructures with the greatest resistance to short stress corrosion crack propagation are predicted to be those in which the bridging stress develops more rapidly with physical crack length. Such microstructures will have smaller grain size and higher $P$ factors. A maximum bridging zone size, which is limited by the failure strain of the ligaments and the crack opening angle, can be simply included in the model. This would cause a loss of shielding with increasing crack length. It has not been implemented here, and the bridging zone size is assumed to be the total crack length.

The consequences of crack bridging can be illustrated using a simple linear elastic fracture mechanics model $[4,5]$. The critical threshold stress, $\sigma_{t}$, is the applied stress necessary to increase the net crack tip stress intensity factor above $K_{I S C C}$ (equation 4), which is assumed to be small. This represents a stress corrosion criteria for plastic strain at the crack tip. A semi-circular crack, radius $a$, is assumed.

$$
\sigma_{\text {th }}=\frac{\sqrt{2 \pi}\left(K_{s h}+K_{I S C C}\right)}{\sqrt{a}} \text { where } K_{s h}=\sigma_{b} \sqrt{a / 2 \pi}
$$

This model is closely related to percolation-like models for intergranular stress corrosion cracking, in terms of the relative effects of microstructure parameters. However, it incorporates the shielding from crack bridging, includes the effects of applied stress magnitude, and can be applied to short cracks in residual stress gradients.

\section{Residual Stress}

The model can be used to interpret the observed effects of surface residual stress on crack behaviour. The predicted variation of threshold stress with crack length is shown in Figure 4 for the as-received microstructure, with no residual stress. The maximum bridging stress has been chosen to be $125 \mathrm{MPa}$ to fit the maximum observed crack length at an applied stress of $100 \mathrm{MPa}$. At $200 \mathrm{MPa}$, the samples exhibited unstable stress corrosion crack propagation. The cracks that developed in a typical residual stress field induced by surface milling are shown in Figure 5. The sample was tested under an applied stress of 100 $\mathrm{MPa}$. The residual stress was measured by $\mathrm{X}$-ray diffraction and successive removal of the surface through electropolishing [e.g 8] The closure stress, $\sigma_{c l}$, which results from the residual stress field, was obtained by integrating the residual stress, $f(R S)$ (Figure $5 b$ ) over the crack length (equation 5 ).

$$
\sigma_{c l}=\frac{1}{a} \int_{0}^{a} f(R S) d a
$$

This has been added to the crack bridging stress to predict the variation of crack propagation threshold stress with crack length, using the same microstructure parameters as the stress-free surface (Figure 4). A significant effect of the sub-surface compressive stress is apparent, and both a reduction in crack length and an increase in the threshold stress for unstable crack nucleation are predicted.. The maximum crack length observed at $100 \mathrm{MPa}$ is compared with the prediction, with good, perhaps fortuitous, agreement. The analytical model is therefore consistent with the observed effect of surface residual stress on stress corrosion crack behaviour.

\section{Finite Element Modelling}

The simple analytical model makes a number of significant assumptions, including the use of linear elastic fracture mechanics, a microstructure independent maximum bridging stress and a rate of bridge development determined by the average separation of bridges. Two-dimensional [9] and three-dimensional $[4,10]$ finite element intergranular crack propagation models have therefore been developed, to verify and quantify the mechanical effect of crack bridging ligaments on short crack development and interaction. The aim is to ultimately provide a tool for 3D theoretical investigations of the interaction between multiple cracks and the influence of residual stress gradients.

The models assume a critical crack tip strain for crack propagation, which depends on the relative degree of sensitisation. Binary resistant/susceptible behaviour is currently assumed to be representative of fully sensitised microstructures. Typical data for the 2D model is shown in Figure 6, which illustrates the effects of susceptible boundary fraction and grain size on the crack driving force. A similar effect of susceptible boundary fraction is observed in three-dimensions (Figure 7), although the predicted degree of shielding is smaller for the same grain boundary properties. An effect of grain size, comparable to that observed in 2D, is also expected in 3D. Verification of this is currently underway, as it requires substantial computational effort.

These results confirm the mechanical shielding effect of crack bridging, and the model has therefore been used to investigate residual stress effects. Typical data is given in Figure 8, for cracks propagating in a 
similar stress field to Figure 5. The behaviour of a typical crack developed without residual stress, and the crack population developed with residual stress are compared. The 2D model with residual stress shows significant surface cracking, which rarely penetrates the sub-surface compressive stress region. This is consistent with the observed behaviour (Figure 5), and implies that the effects of stress corrosion crack propagation in residually stressed components may be predicted with appropriate tuning of the model parameters.
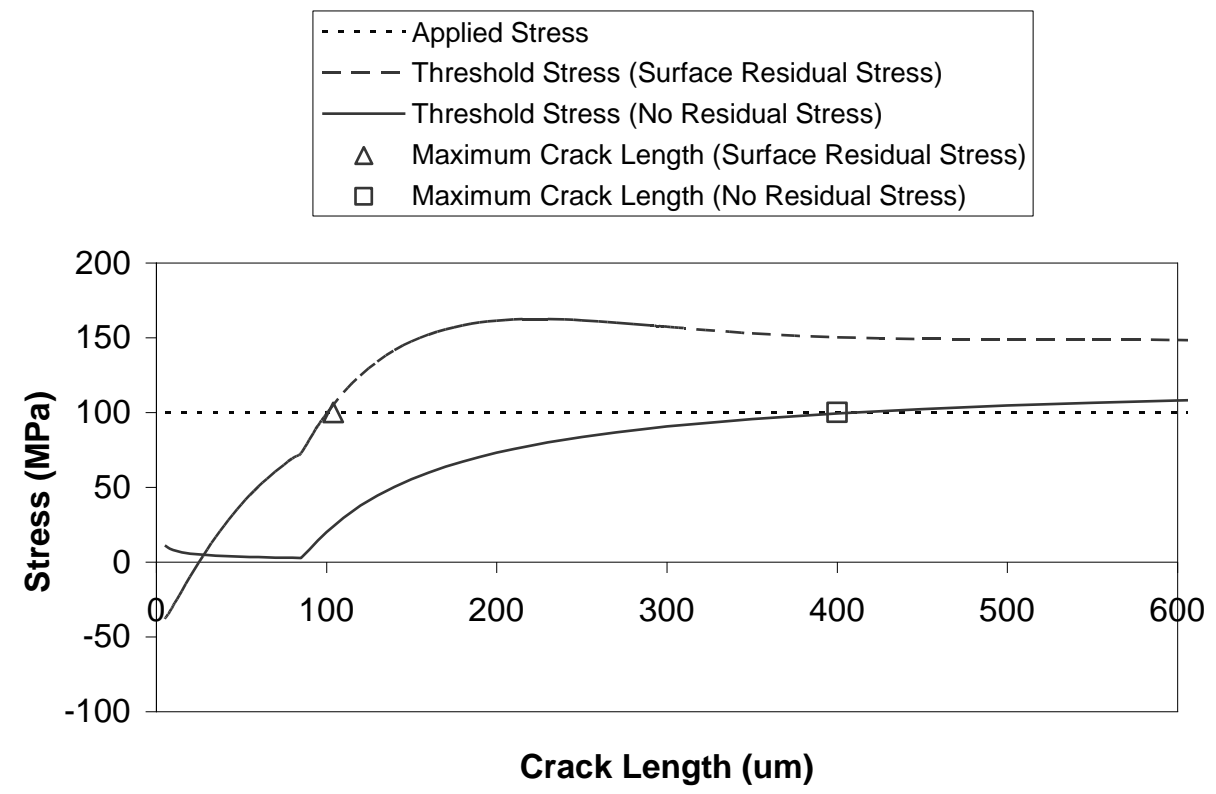

Figure 4: The predicted variation of crack propagation threshold stress with crack length for as-received microstructure with and without surface residual stress. The maximum crack length observed at an applied stress of $100 \mathrm{MPa}$ is shown. The maximum bridging stress has been assumed to be $125 \mathrm{MPa}$.
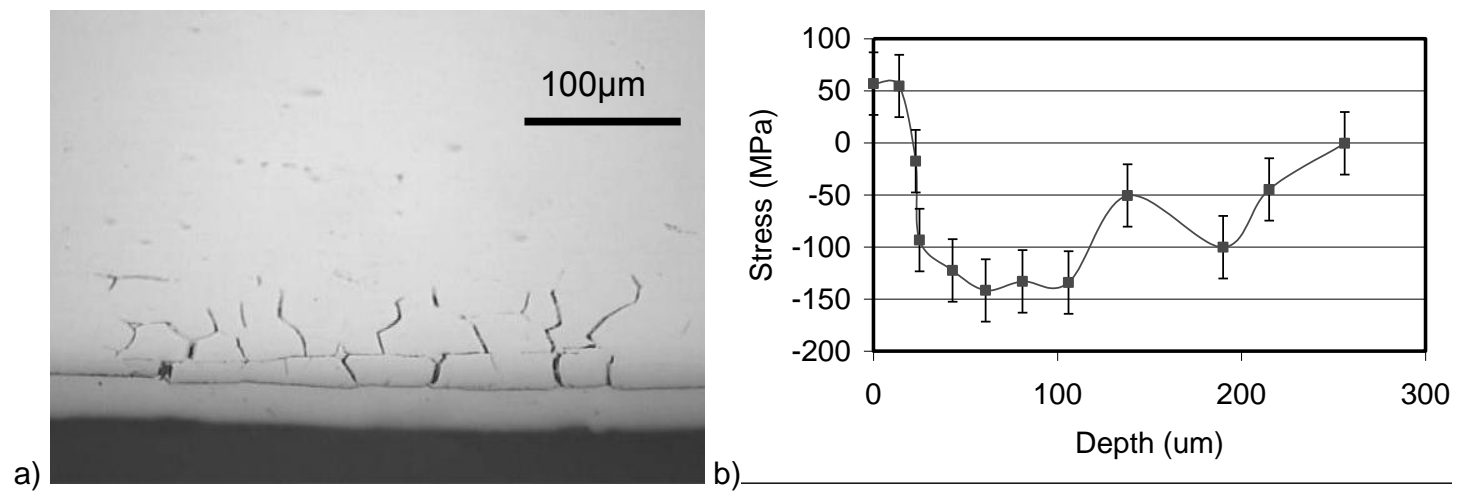

Figure 5: Effect of residual stress on crack propagation. a) crack development in as-received microstructure, fully sensitised, tested in $0.1 \mathrm{M}$ potassium tetrathionate solution, acidified with diluted sulphuric acid to $\mathrm{pH}$ 2.5 , at $100 \mathrm{MPa}$ for 144 hours. b) the measured residual stress field perpendicular to the crack plane. A nickel layer was deposited after testing for edge retention during metallographic sectioning. 


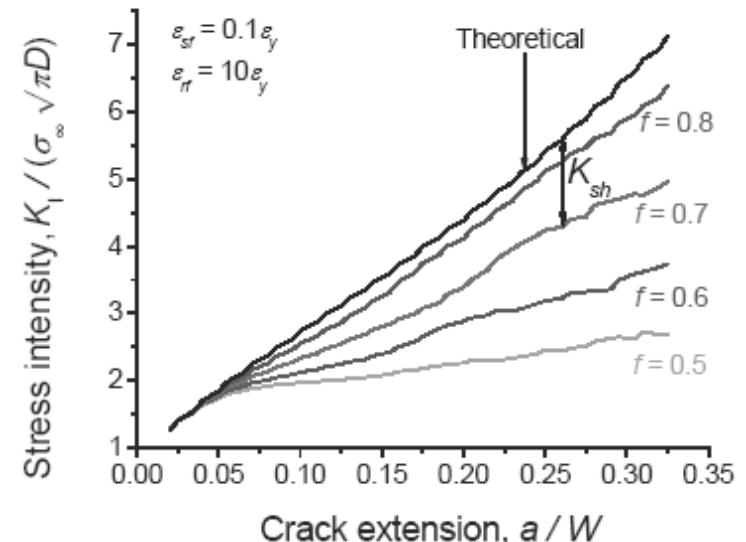

a)

Figure 6: Two dimensional model for the development of an intergranular stress corrosion crack. The failure strain of susceptible boundaries is $1 \%$ of the failure strain of resistant boundaries. Comparison is made with a non-bridged "theoretical" crack. Predications are shown for a) the effects of different fractions ( $f$ ) of susceptible grain boundaries on the development of the normalised crack tip stress intensity factor $(K)$ and crack shielding $\left(\mathrm{K}_{\mathrm{sh}}\right)$ with applied stress $\left(\sigma_{\infty}\right)$ for a microstructure with grain size $(\mathrm{D})$ as the crack length increases $(W=50 D), b)$ the effect on grain size $(D)$ on the normalised crack driving force with increasing crack size for $50 \%$ susceptible boundaries $(d=40 \mu \mathrm{m}, W=50 \mathrm{~d})$.

a)

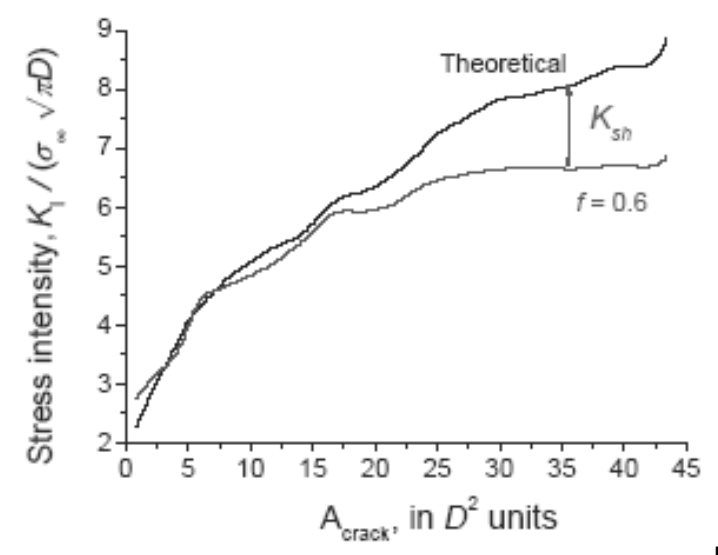

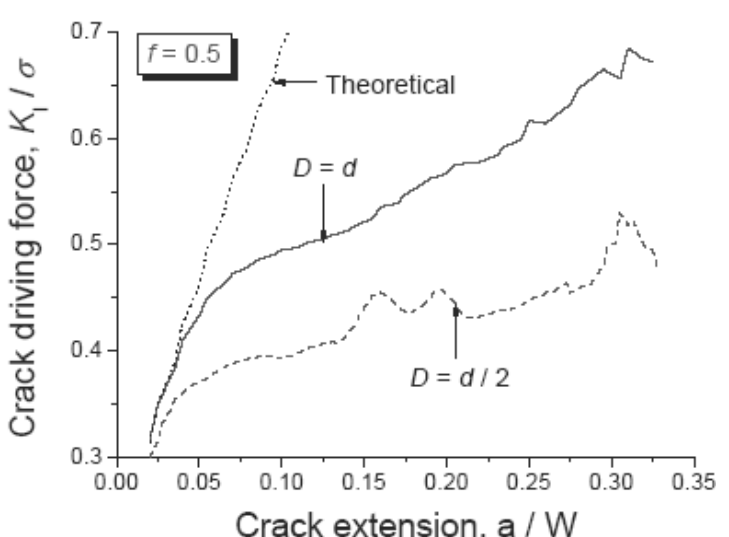

b)

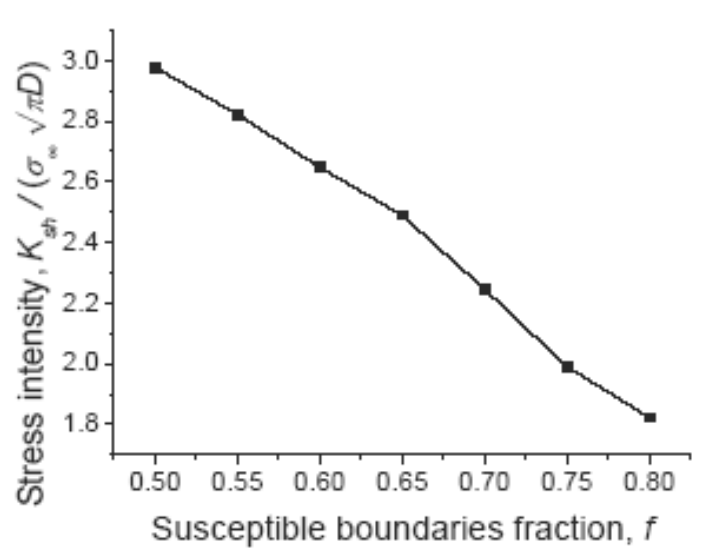

b)

Figure 7: Three-dimensional model for the development of an intergranular stress corrosion crack. The boundary properties are as in Figure 6 . Predictions for a) crack tip stress intensity factor for a microstructure with $60 \%$ susceptible boundaries, b) effect of the fraction of susceptible boundaries on the magnitude of crack shielding $\left(K_{s h}\right)$ for equivalent crack size $\left(A=40 D^{2}\right)$.

a)

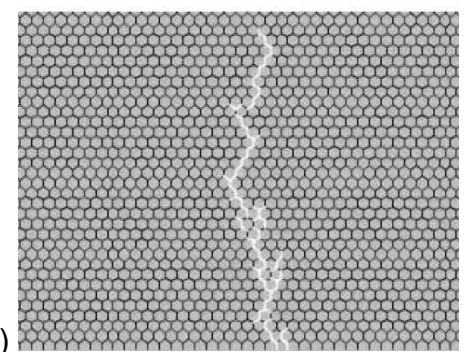

b)

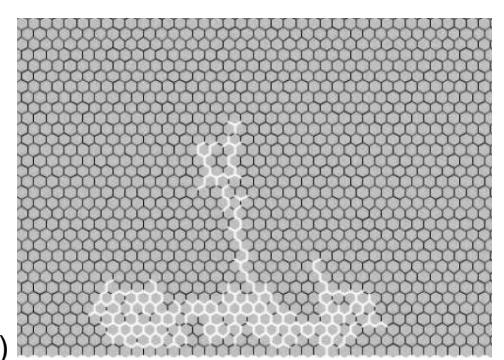

Figure 8: Typical results for the development of cracks using the 2D model with crack bridge development for a) applied tensile stress, b) applied tensile stress with sub-surface compressive residual stress. 


\section{Summary and Conclusion}

The propagation of short intergranular stress corrosion cracks is influenced by microstructure and residual stress. A simple analytical model has been proposed which is consistent with the observed behaviour. Two and three-dimensional finite element models for crack behaviour have also been developed, guided by high resolution observations of the mechanism of crack propagation. These models are being validated using test specimens with well characterized microstructures and surface residual stress distributions.

\section{Acknowledgments}

The authors are grateful to EPSRC, Rolls Royce PIc, BNFL and Serco Assurance for their independent support of the research described in this paper. The opinions expressed are those of the authors.

\section{References}

1. T. Watanabe, An approach to grain-boundary design for strong and ductile polycrystals, Res. Mechanica, (1984), 47.

2. F.J. Humphreys, Review - Grain and subgrain characterisation by electron backscatter diffraction, Journal of Materials Science, (2001), 36, 3833.

3. D.L. Engelberg, T.J. Marrow, L. Babout and R.C. Newman, Grain Boundary Engineering for Crack Bridging: Intergranular Corrosion and Stress Corrosion Crack Path Dependencies, $16^{\text {th }}$ International Corrosion Conference, (2005), Beijing, China.

4. T.J. Marrow, L. Babout, A.P. Jivkov, P. Wood, D. Engelberg, N. Stevens, P.J. Withers, Three dimensional observations and modelling of intergranular stress corrosion cracking in austenitic stainless steel, E-MRS Spring Meeting, Strasbourg, France, (2005).

5. D.L.Engelberg, T.J.Marrow, R.C.Newman, L.Babout, A new model for IGSCC propagation, Second International Conference on Environment- Induced Cracking of Metals, EICM-2, (2004), Banff, Canada

6. G. Palumbo, P.J. King, K.T. Aust, U. Erb, P.C. Lichtenberger, Grain-boundary design and control for intergranular stress-corrosion resistance, Scripta Metall. Mater. 25 (1991) 1775-1780.

7. V.Y. Gertsman, K. Tangri, Modelling of intergranular damage propagation, Acta Mater. 45 (1997) 4107-4116.

8. M. Kuroda, T.J. Marrow and A.H. Sherry, Effects of surface finish on fatigue in austenitic stainless steels, ECF 16, (2006).

9. A.P. Jivkov, N.P.C. Stevens and T.J. Marrow, The roles of microstructure and mechanics in intergranular stress corrosion cracking, First International Conference on the Simulation of Electrochemical Processes (ElectroCor 05), Cadiz, Spain, (2005).

10. A.P. Jivkov, N.P.C. Stevens and T.J. Marrow, A three-dimensional computational model for intergranular stress corrosion cracking, submitted to Computational Materials Science (2006). 